\title{
Cross-sex hormone therapy affects body fat distribution in
}

\section{transgender persons}

M. Klaver ${ }^{\star}$, M.J.H.J. Dekker ${ }^{1}$, N. M.Nota ${ }^{1}$, A.D. Fisher ${ }^{2}$, T. Schreiner ${ }^{3}$, G. T'sjoen ${ }^{4}$, M. den Heijer ${ }^{1}$

${ }^{1}$ Center of Expertise on Gender Dysphoria, VU University Medical Center, Amsterdam, the Netherlands. ${ }^{2}$ Sexual Medicine and Andrology Unit, Department of Experimental, Clinical and Biomedical Sciences, University of Florence, Florence, Italy. ${ }^{3}$ Department of Endocrinology, Oslo University

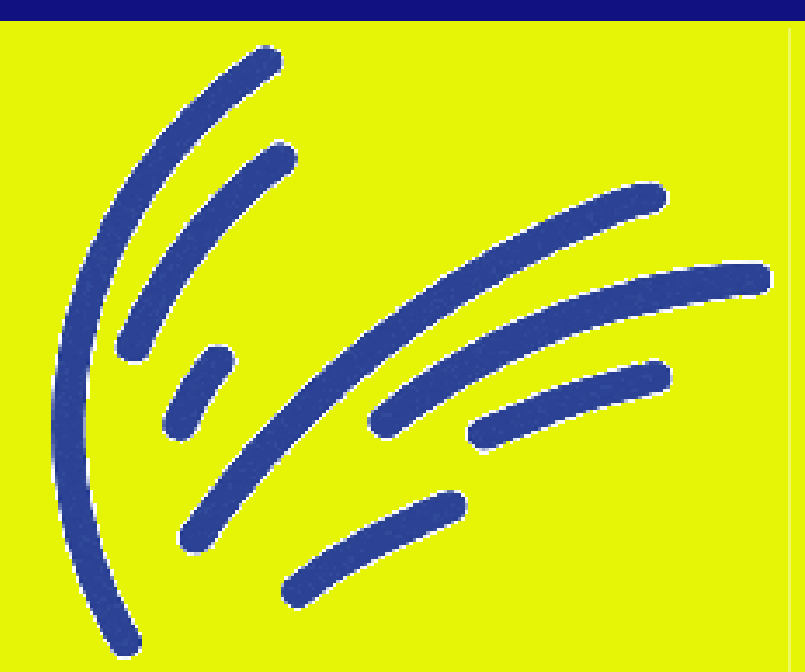
Hospital, Oslo Norway. ${ }^{4}$ Department of Endocrinology, Ghent University Hospital, Ghent, Belgium.*ma.klaver2@vumc.nl VU university medical center

\section{Background}

Fat distribution is an important secondary sex characteristic, which is generally peripherally or pear-shaped (gynoid) in females and centrally or apple-shaped (android) in males. Total body fat increases in male-to-females (MtFs) and decreases in female-to-males (FtMs) during cross-sex hormone therapy (CSHT), approaching body fat amounts of the desired sex. However, changes in android or gynoid fat distribution might be a better measure for masculinization and feminization than changes in amount of body fat per se. As yet, it is unknown what are the exact effects of CSHT on fat in the androidand gynoid region and whether these outcomes are more affected by $\mathrm{CSHT}$ than other measures.

\section{Aim}

To examine the effects of CSHT in MtFs and FtMs on android fat and gynoid fat and to compare these outcomes as measures of masculinization and feminization to other measures of body composition.

\section{Methods}

Population: This prospective study (ENIGI) included 108 patients that completed one year of CSHT.

Medication: $\quad 51 \mathrm{MtFs}$ received Androcur® $50 \mathrm{mg} /$ day and Progynova $₫(4 \mathrm{mg} /$ day $)$ or Systen $₫(100 \mathrm{mcg} / \mathrm{h})$, while 57 FtMs were treated with Androgel $₫(50 \mathrm{mg} /$ day $)$, Sustanon $\AA(250 \mathrm{mg} / 2$ weeks $)$ or Nebido® (1000mg/12 weeks).

Measurements: At the start and after one year of CSHT anthropometrics were measured and a whole body DEXA was obtained, in which android fat and gynoid fat were measured

\section{Android region:}

Area between the ribs and the pelvis. Upper demarcation: $20 \%$ of the distance between the iliac crest and the neck. Lower demarcation: top of the pelvis.

Gynoid region:

Hip and upper thigh region. Upper demarcation: below the top of the iliac crest at a distance of 1.5 times the android height. Total height: two times the height of the android region.
Male-to-female transgender persons
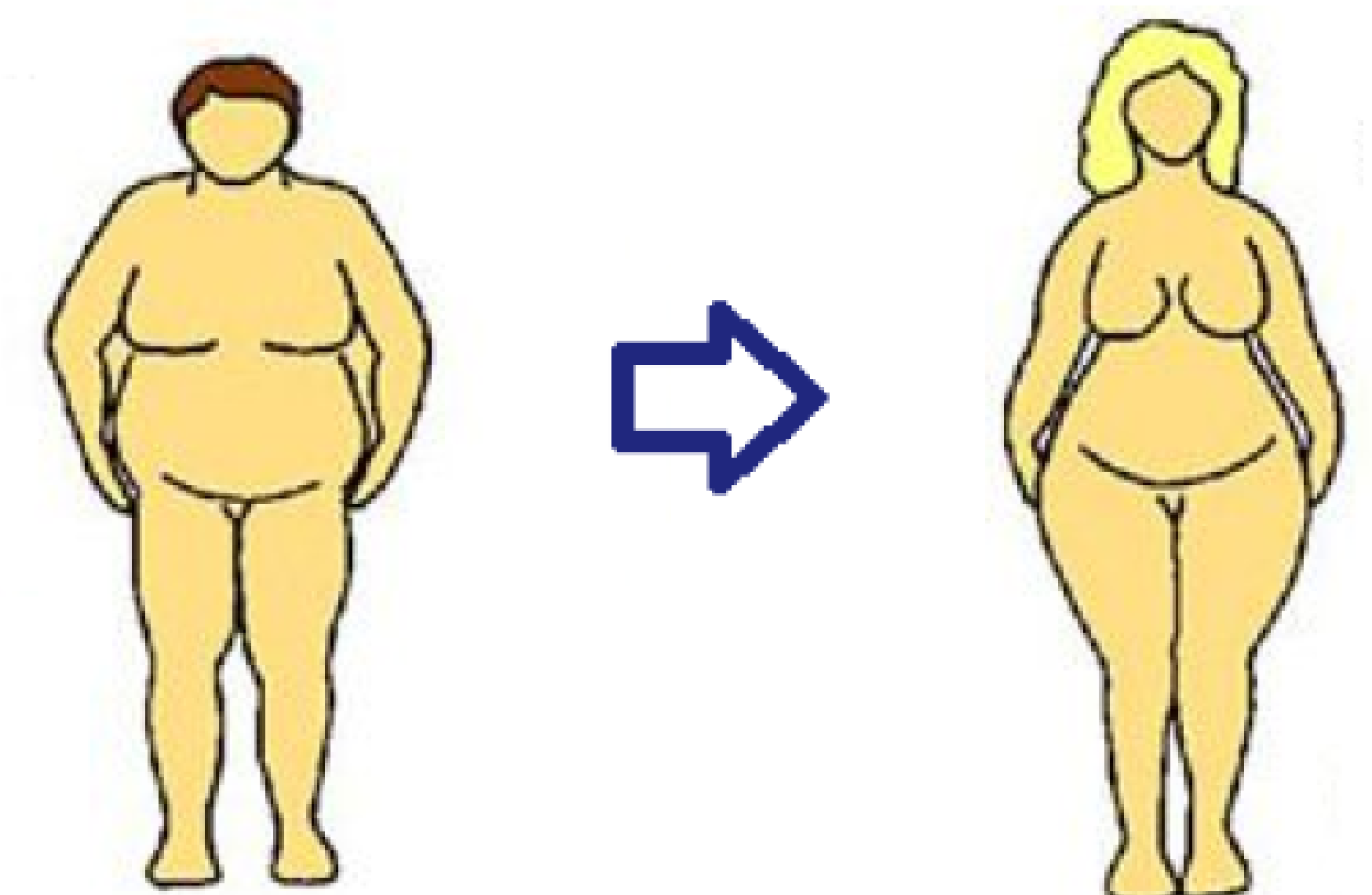

Android fat: $+0.2 \mathrm{~kg}(0.1 ; 0.4)$

from $1.4 \mathrm{~kg}$ to $1.6 \mathrm{~kg}$

Gynoid fat: $+0.9 \mathrm{~kg}(0.6 ; 1.3)$

from 3.0 to $3.9 \mathrm{~kg}$

Total body fat: $+4.0 \mathrm{~kg}(2.5 ; 6.1)$ from 17.6 to $21.6 \mathrm{~kg}$ Waist-hip ratio: $-0.03(-0.01 ;-0.05)$ from 0.86 to 0.83

Female-to-male transgender persons
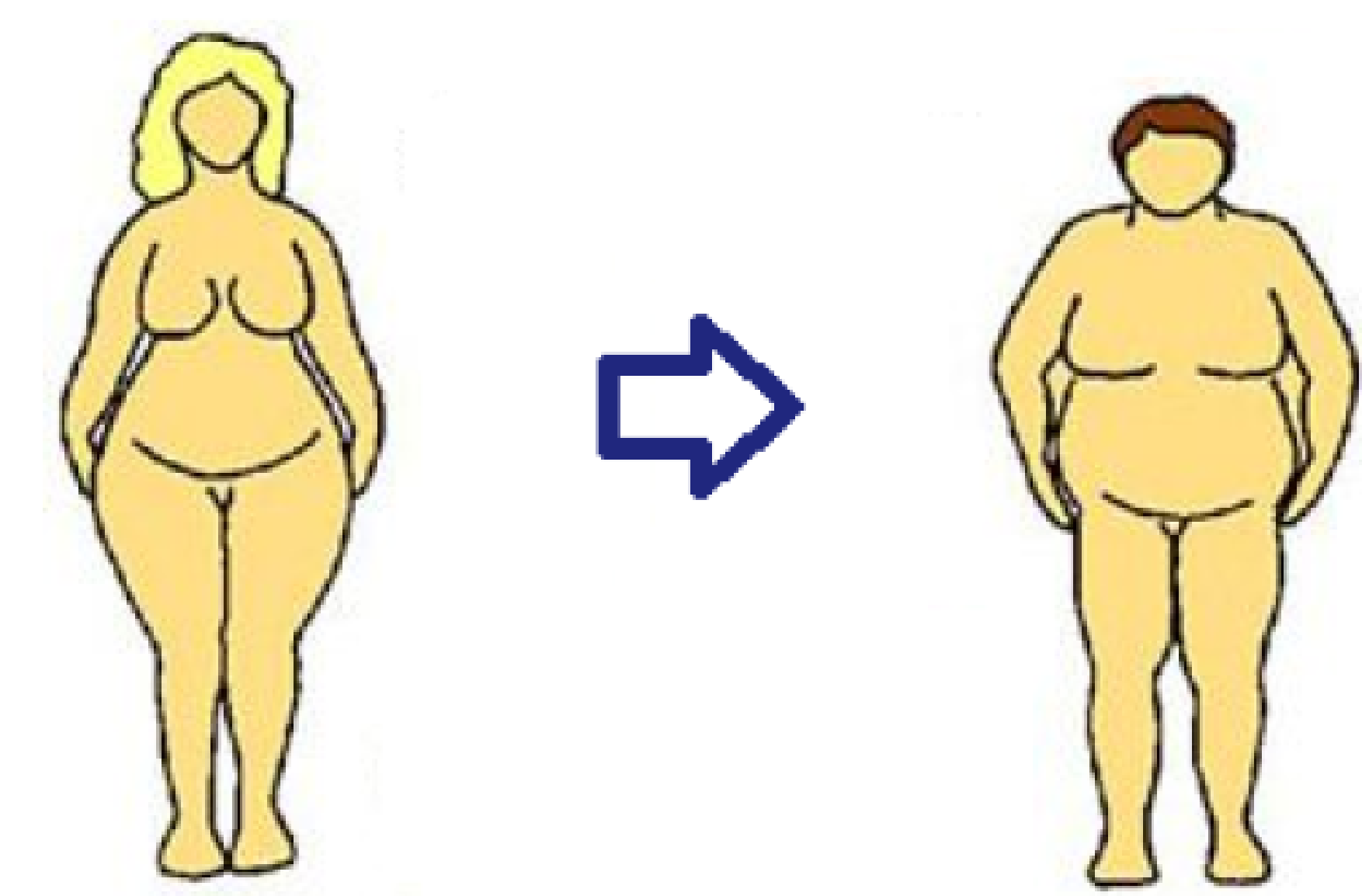

Android fat: $+0.1 \mathrm{~kg}(-0.02 ; 0.2)$

from 1.6 to $1.7 \mathrm{~kg}$

Gynoid fat: $-0.6 \mathrm{~kg}(-0.5 ;-0.7)$

from 4.6 to $4.0 \mathrm{~kg}$

Total body fat: $-1.9 \mathrm{~kg}(-0.8 ;-2.5)$ from 23.2 to $21.3 \mathrm{~kg}$ Waist-hip ratio: $+0.02(-0.01 ; 0.03)$ from 0.81 to 0.83

Changes in all measures of body composition in MtFs

\begin{tabular}{llll}
\hline & Start of therapy & Change in \% & Confidence interval \\
\hline Body weight $(\mathrm{kg})$ & $73.3 \mathrm{~kg}$ & $+3 \%$ & $0.4 \% ; 5 \%$ \\
BMI $(\mathrm{kg} / \mathrm{m} 2)$ & 23.0 & $+1 \%$ & $-3 \% ; 2 \%$ \\
Total body fat $(\mathrm{kg})$ & $17.6 \mathrm{~kg}$ & $+23 \%$ & $16 \% ; 31 \%$ \\
Gynoid fat $(\mathrm{kg})$ & $3.0 \mathrm{~kg}$ & $+30 \%$ & $22 \% ; 39 \%$ \\
Android fat $(\mathrm{kg})$ & $1.4 \mathrm{~kg}$ & $+14 \%$ & $5 \% ; 25 \%$ \\
Waist $(\mathrm{cm})$ & 81.5 & $-1 \%$ & $-3 \% ; 1 \%$ \\
Hip $(\mathrm{cm})$ & 95.1 & $+3 \%$ & $1 \% ; 5 \%$ \\
WHR & 0.86 & $-4 \%$ & $-6 \% ;-1 \%$
\end{tabular}

Changes in all measures of body composition in FtMs

\begin{tabular}{llll}
\hline & Start of therapy & Change in \% & Confidence interval \\
\hline Body weight $(\mathrm{kg})$ & $68.9 \mathrm{~kg}$ & $+5 \%$ & $3 \% ; 7 \%$ \\
BMI $(\mathrm{kg} / \mathrm{m} 2)$ & 24.8 & $+5 \%$ & $4 \% ; 6 \%$ \\
Total body fat $(\mathrm{kg})$ & $23.2 \mathrm{~kg}$ & $-8 \%$ & $-12 \% ;-3 \%$ \\
Gynoid fat $(\mathrm{kg})$ & $4.6 \mathrm{~kg}$ & $-13 \%$ & $-17 \% ;-9 \%$ \\
Android fat $(\mathrm{kg})$ & $1.6 \mathrm{~kg}$ & $+4 \%$ & $-2 \% ; 11 \%$ \\
Waist $(\mathrm{cm})$ & $79.9 \mathrm{~cm}$ & $+2 \%$ & $-1 \% ; 5 \%$ \\
Hip $(\mathrm{cm})$ & $98.7 \mathrm{~cm}$ & $0 \%$ & $-2 \% ; 3 \%$ \\
WHR & 0.81 & $+2 \%$ & $-1 \% ; 4 \%$
\end{tabular}

Conclusion

In MtFs, CSHT causes a more gynoid fat distribution with a decrease in waist-hip ratio. In FtMs, a trend towards a more male fat distribution with a decrease in gynoid fat is observed. Gynoid fat shows the largest percentual change after one year of CSHT in MtFs and FtMs and seems to be a sensitive marker for cross-sex hormone action. 